\title{
DIE GRONDTEKS VAN DIE AFRIKAANSE NUWE TESTAMENT
}

Voordat daar met die vertaling van 'n dokument begin kan word, is dit noodsaaklik om die teks, die presiese bewoording van die dokument, vas te stel. Die vasstelling van die teks is soveel te meer belangrik wanneer die dokument wat vertaal word, ' $n$ ou dokument is, wat voor die uitvinding van die boekdrukkuns geskryf is en waarvan die oorspronklike dokument reeds verlore is. So 'n dokument is van geslag tot geslag deur middel van handkopieë oorgelewer en in hierdie kopieproses het daar talle foute in die manuskripte van die betrokke dokument ingesluip. Aangesien die oorspronklike verlore is, moet alle beskikbare manuskripte van so 'n dokument versamel word, en met mekaar vergelyk word. Op die plekke waar hierdie manuskripte van mekaar verskil, moet dan bepaal word watter manuskrip waarskynlık die lesing van die oorspronklike dokument bevat. Nadat daar op hierdie wyse bepaal is wat die presiese bewoording van die oorspronklike dokument was, kan daar eers met die vertaling van die betrokke dokument begin word. Hierdie probleem staar alle vertalers van klassieke dokumente, maar ook vertalers van die Nuwe (en Ou) Testament in die gesig.

\section{Die Griekse Nuwe Testament}

\subsection{Manuskripte van die Griekse Nuwe Testament}

Van die meeste klassieke geskrifte het daar bitter min manuskripte behoue gebly. Daar is talle geskrifte waarvan selfs geen enkele fragment vandag meer beskikbaar is nie. Met die Griekse Nuwe Testament is dit egter anders gesteld. Die Gewer van die Woord het op ' $n$ heel besondere wyse toegesien dat sy Woord nie vergaan nie. Vandag is daar reeds soveel as $\mathbf{5 3 6 6}$ manuskripte van die Griekse Nuwe Testament gevind. Alhoewel talle van hierdie manuskripte slegs fragmente is, bevat die oorgrote meerderheid van hierdie manuskripte of die geheel van die Nuwe Testament of ten minste 'n hele boek van die Nuwe Testament. Die probleem is egter dat geen twee van hierdie manuskripte in alle opsigte met mekaar ooreenstem nie. Reeds in 1717 het die Britse tekskritikus, John Mill, byvoorbeeld, ' $n$ teks gepubliseer waarin hy alle teksverskille wat aan hom bekend was, gevoeg het. Alhoewel veel minder manuskripte 
as vandag aan hom bekend was, het sy teks reeds om en by 30,000 variante lesings bevat.

\subsubsection{Die Textus Receptus '}

Die bestaan van hierdie variante lesings in die manuskripte van die Griekse Nuwe Testament het onmiddellik na die uitvinding van die Boekdrukkuns deur Gutenberg in die 15e eeu probleme vir mense wat 'n teks van die Griekse Nuwe Testament wou publiseer, meegebring. Hoe meer manuskripte deur die loop van die eeue ontdek is, hoe groter het die probleme vir samestellers van die teks geword. Dit het daartoe aanleiding gegee dat verskillende tekskritici met verskillende metodes probeer het om die oorspronklike teks van die Nuwe Testament saam te stel.

Die eerste poging om die teks van die Griekse Nuwe Testament te herstel, was dié van Francisco Ximenes de Cisneros, 'n Spaanse kardinaal. Ximenes het 'n poliglot ('n Bybel waarin die Nuwe Testament in verskillende tale aangebied is) saamgestel. Stunica het die samestelling van die Griekse teks vir hierdie uitgawe van Ximenes behartig. Alhoewel hy reeds in 1514 met sy teks gereed was, moes hy vir sanksie van die pous wag voordat die teks amptelik versprei kon word. Die teks is gevolglik eers sewe jaar later, in 1521, amptelik gepubliseer. Die manuskripte wat hy vir die samestelling van sy teks gebruik het, was almal uit die laat-middeleeue en dus meer as 'n millenium van die oorspronklike verwyder.

Met die eerste amptelik-gepubliseerde teks was dit geensins beter gesteld nie. In 1514 het 'n drukker in Basel, Johann Froben te hore gekom van die teks wat die kardinaal op die punt was om te publiseer. Hy het egter onmiddellik met die bekende humanis, Desiderius Erasmus, in verbinding getree en voorgestel dat Eramus probeer om die kardinaal voor te spring en so die eer te verkry dat sy naam in die annale van die geskiedenis opgeteken sal staan as die eerste om 'n teks van die Griekse Nuwe Testament te publiseer. Erasmus het die uitdaging aanvaar en in 1516, na slegs ses maande se werk, word hierdie teks geplbbliseer. Erasmus het sy teks op slegs ses manuskripte, almal uit die laat-middeleeue, gebaseer. In die voorwoord van hierdie teks erken hy self dat die teks haastig en onnoukeurig saamgestel is. Die haas waarmee hy die werk voltooi

'n Goeie beskrywing van die geskiedenis van die TR kan in Jordaan, 1975; Metzger, 1968.95 - 118 en Aland 8 Aland, $1982: 13-16$ gevind word. 
het, kan waarskynlik die beste geillustreer word deur na die laaste hoofstuk van die Bybel te verwys. In die manuskrip waarop Erasmus sy teks van Die Openbaring gebaseer het, het die laaste ses verse van hierdie boek ontbreek. In sy haas om die teks te voltooi, het hy nie 'n ander manuskrip probeer opspoor nie, maar die betrokke woorde uit die Latyn in Grieks vertaal.

In 1546 publiseer Stephanus, die Latynse naam van Robert Estienne 'n teks van die Griekse Nuwe Testament. Hierdie teks was egter hoofsaaklik 'n reproduksie van die vierde uitgawe van Erasmus se teks. Stephanus se vierde uitgawe het die versindelings, wat vandag algemeen aanvaar word, bevat. Stephanus se grondteks is as grondteks vir die vertaling van die King James Version van 1611 gebruik.

Die hervormer en opvolger van Calvyn in Genéve, Theodore de Beza, publiseer in 1565 die eerste van 10 uitgawes van die Griekse Nuwe Testament. Op sy beurt maak hy egter weer hoofsaaklik van Stephanus ze vierde uitgawe gebruik. Die teks van Beza is uiteindelik as grondteks vir die vertaling van die bekende Nederlandse Statevertaling gebruik.

Bonaventure en Abraham Elsevier publiseer in 1624 in Leiden ' $n$ teks wat hoofsaaklik op die teks van Beza gebaseer is. In die voorwoord van die tweede uitgawe in 1633 plaas hulle 'n advertensie om die teks beter te laat verkoop. Die volgende kort sinnetjie vorm die kern van hierdie advertensie " $U$ HET NOU ' $N$ TEKS WAT DEUR ALMAL AANVAAR WORD". As gevolg van hierdie woorde het hierdie teks gou as die Textus Receptus, die Latyn vir aanvaarde teks, bekend geraak.

Die Textus Receptus is spoedig as ' $n$ teks met feitlik kanoniese gesag beskou en vir feitlik twee eeue lank durf niemand 'n teks publiseer wat van hierdie teks verskil het nie. Die teks het geheel en al buite rekening gelaat

- dat hierdie teks op onwetenskaplike wyse saamgestel is;

- dat geen ou manuskrip in die proses van scmestelling geraadpleeg is nie;

- en dat die woorde wat die algemene aanvaarding en gesag aan die teks verleen het, eintlik as advertensie bedoel is, en in wese niks 
oor die aard of betroubaarheid van die teks gesê het nie. Soos later aangetoon sal word, het die Textus Receptus ook as grondteks van die Afrikaanse vertaling van 1933 gedien.

\subsubsection{Die Kritiese Teks ${ }^{2}$}

Spoedig na die publikasie van die Textus Receptus het daar egter stemme teen die gesag van hierdie teks opgegaan. Die ontdekking van ouer manuskripte het tekskritici laat besef dat die Textus Receptus ' $n$ swak en onbetroubare teks is, omdat daar uitgevind is dat hierdie ouer manuskripte, waarvan sommige uit die vierde eeu dateer, op baie plekke van die Textus Receptus verskil. $\mathrm{Na}$ 'n proses van stryd teen die oorheersing van die Textus Receptus, wat vir ongeveer twee eeue geduur het, publiseer die Duitser, Karl Lachmann in 1831 die eerste teks wat met behulp van wetenskaplike metodes saamgestel is en wat hoofsaaklik op die oudste en beste manuskripte gebaseer is. Hierdie teks het op talle plekke van die Textus Receptus afgewyk.

Die groot deurbraak teen die oorheersing van die Textus Receptus kom egter in 1881. In hierdie jaar publiseer twee Britse tekskritici, Brooke Foss Westcott en Fenton John Anthony Hort, 'n teks wat hoofsaaklik op die twee oudste en beste manuskripte, codex Vaticanus en Sinaiticus, gegrond is. Hierdie manuskripte dateer uit die vierde eeu en was die beste wat in die negentiende eeu bekend was. Meer belangrik as hulle teks was egter die handleiding wat saam met hierdie teks verskyn het. Daarin het hulle die beginsels waarvolgens hulle gewerk het, noukeurig uiteengesit. In hierdie uiteensetting het hulle suksesvol aangetoon dat die genoemde twee manuskripte nie alleen chronologies nie, maar ook inhoudelik nader aan die oorspronklike staan as die Textus Receptus. Hierdie teorie het die Textus Receptus finaal as 'n swak en onbetroubare teks uitgewys. Na bykans twee eeue se stryd is die Textus Receptus finaal verwerp.

2 'n Goeie oorsig oor die die ontwikkeling van die kritiese benadering in die $18 \mathrm{e}$ en $19 \mathrm{e}$ eeu kan in Meizger, 1968:119 - 136 en Aland \& Aland, 1982:16 - 29 gevind word. 


\subsubsection{Die nuwe standaardteks ${ }^{3}$}

Die twintigste eeu sou gekenmerk word deur die ontdekking van vele manuskripte van die Nuwe Testament. Veral twee ontdekkings is belangrik:

- In 1930 - 31 bring Sir Chester Beatty 'n uiters waardevolle versameling papiri aan die lig. Onder hulle was drie papiri wat dele van die Nuwe Testament bevat het: p45, p46 en p47. Die oudste van hierdie papiri, p47, dateer uit die vroeg-derde eeu.

- In 1955-56 bring Martin Bodmer die tweede belangrike groep papiri aan die lig. Drie van die belangrikste manuskripte van die Nuwe Testament wat nog bekend is, was onder die groep, naamlik p66. die oudste manuskrip van die Evangelie volgens Johannes uit ongeveer die jaar 200, p72, die oudste beskikbare manuskrip van die Judas- en Petrusbriewe, en p75, die oudste beskikbare manuskrip van die Evangelie volgens Lukas, uit die jare $175-225$.

Noukeurige ontleding van hierdie manuskripte het aangetoon dat hulle in hoofsaak met die manuskripte waarop Westcott en Hort hul teks gebaseer het, codex Vaticanus en Sinaïticus, ooreenstem. Hierdie manuskripte het die gevolgtrekking dat die Textus Receptus nie 'n getroue weergawe van die oorspronklike Griekse Nuwe Testament is nie, in hoofsaak bevestig.

Tog is daar bepaalde prominente verskille tussen hierdie nuut-ontdekte manuskripte en codex Vaticanus en Sinaiticus. Die gevolg was dat nuwe tekste saamgestel moes word, waarin hierdie nuut-verworwe kennis na behore verdiskonteer kon word. In die vyftigerjare van hierdie eeu het die gedagte gevolglik ontstaan dat die voorste tekskritici in 'n span moet saamwerk om 'n uitgawe van die Griekse Nuwe Testament daar te stel, waarin die nuutste metodologiese ontwikkelings en die nuutste manuskrip-ontdekkings verdiskonteer kon word. Die doel was om 'n teks hoofsaaklik vir vertaling van die Nuwe Testament saam te stel.

Onder beskerming van die Verenigde Bybelgenootskappe en onder leiding van die Duitser Kurt Aland het vyf van die voorste tekskritici

3 'n Goeie bespreking van die Nuwe-Testamentiese Tokskritiak in die 200 eau on die "nuwe standaardteks" kan in Metzger. 1968: 137 - 165 en Aland \& Aland. 1982: 36 - 46 gevind word. 
jaarliks byeengekom om aan hierdie projek te werk. Die eerste resultate is in 1966 gelewer met die publikasie van die eerste uitgawe van The Greek New Testament deur die Verenigde Bybelgenootskappe. Twee jaar later, in 1968, het 'n tweede uitgawe gevolg, en in 1975 is die derde en tot sover laaste uitgawe gepubliseer. 'n Derde gekorrigeerde uitgawe is in 1983 gepubliseer. Hierdie uitgawe het egter dieselfde teks as die uitgawe van 1975 en is slegs ten opsigte van kritiese apparaat gekorrigeer. Darom word dit nie as ' $n$ vierde uitgawe aangebied nie. Hierdie teks staan vandag as die "nuwe standaardteks" bekend en dit word aanvaar dat hierdie teks waarskynlik nader aan die teks van die oorspronklike Griekse Nuwe Testament staan as enige ander teks wat gepubliseer is. Hierdie teks is as grondteks vir talle moderne vertalings, onder andere die nuwe Afrikaanse vertaiing, gebruik.

\section{Die Afrikaanse Nuwe Testament}

\subsection{Die Afrikaanse Bybel van 1933}

Literatuur oor die Afrikaanse Bybelvertaling gee maar 'n beskeie plek aan die vertalers se keuse van die grondteks. Dit is egter verstaanbaar, aangesien die keuse van die grondteks sekerlik nie die vertalers se grootste, of selfs een van hul grootste probleme was nie. Sake soos die erkenning van Afrikaans, die wenslikheid van 'n Afrikaanse vertaiing van die Bybel, die vraag of die vertaling uit die Hollands of Grieks moes kom, was veel groter probleme.

Tog blyk dit uit briewe en artikels rondom die Bybelvertaling dat die keuse van die grondteks nie vir die vertalers ' $n$ onbelangrike saak was nie. Die keuse het tussen die Textus Receptus en 'n kritiese uitgawe van die Griekse Nuwe Testament gelê Die reeks artikels deur Totius in die Junie- tot Oktoberuitgawes van Het Kerkblad in 1916 waarin hy Bybelvertaling behandel, getuig hiervan (kyk ook Jordaan 1975:8 - 11, 19 - 25; Nienaber \& Heyl 1961:13v).

Uit die briewe en artikels blyk dit dat daar van die begin af in die regte rigting, $\mathrm{nl}$. 'n kritiese teks, gedink is. In 1878 besluit die Genootskap van Regte Afrikaners byvoorbeeld dat daar uit die grondteks vertaal moet word en nie uit die Nederlandse Statevertaling nie (kyk Nienaber en Heyl 1961:13). In 1885 gee die Genootskap aan S.J. du Toit opdrag om 'n vertaiing uit die grondteks te maak. As grondteks moet hy die teks gebruik wat vir die nuwe Engelse vertaiing gebruik is (Nienaber \& Heyl, 1961:15). 
Hiermee het hulle waarskynlik na die grondteks van die Revised Standard Version verwys wat pas tevore in Engeland verskyn het, en op 'n kritiese teks waaraan Westcott en Hort groot aandeel gehad het, gebaseer was. Hierdie Engelse vertaling, wat aanvanklik bloot as hersiening van die King James Version bedoel is, het uiteindelik op 'n geheel nuwe vertaling uitgeloop. Die publikasie van hierdie vertaling, soos ook die publikasie van die teks van Westcot en Hort, het geweldige emosionele reaksie van die aanhangers van die Textus Receptus en die tradisionele Engelse vertaling uitgelok. Die felste kritiek het waarskynlik van J.W. Burgon (1883) gekom. Sy publikasie, The Revision Revised, wat meer as 500 bladsye beslaan en oor verskillende aspekte van hierdie nuwe vertaling handel, getuig egter op talle plekke van onwetenskaplikheid en herinner baie aan die kritiek wat vandag teen die Nuwe Vertaling gelug word.

Die aanbeveling van die G.R.A. was dus dat daar van 'n kritiese teks gebruik gemaak moet word om die Nuwe Testament in Afrikaans te vertaal. In 1886 maak Oom Lokomotief egter beswaar teen die gebruik van die kritiese grondteks. Sy beswaar was hoofsaaklik op die praktyk gegrond: "Die eintlike toetsteen sal die State-Bybel wees. Veroordeel dié ons, dan is die onderneming 'n sekere mislukking" (kyk Du Toit, 1916a:5). Hierdie beswaar het uiteindelik die deurslag gegee in die keuse van 'n grondteks vir die vertaling van die Nuwe Testament.

$\mathrm{Na}$ die mislukking van S.J. du Toit se vertaling, word daar in 1916 aan die vertalingskommissie opdrag gegee om uit die Hollands en nie die Grieks nie, te vertaal. Hierdie opdrag word in 1920 herhaal (kyk Nienaber en Heyl 1961:32, ev, 37). Veral Totius was gekant teen die gebruik van ' $n$ kritiese teks as grondteks. Benewens dieselfde praktiese beswaar as dié van Oom Lokomotief, huldig Totius ook die standpunt dat die resultate van die Tekskritiek nie vasstaan nie. Die vordering op die gebied van die Nuwe-Testamentiese Tekskritiek het hom nog nie oortuig dat die Textus Receptus finaal verwerp moet word nie. 'n Derde beswaar van sy kant was dat die verskille tussen die kritiese teks en die Textus Receptus so gering is, dat dit nie werklik saak maak watter teks gebruik word nie: ongeveer 60 tot 70 plekke het saakverskil ingehou, terwyl die res van die plekke slegs tot woordverskil beperk was (kyk Du Toit, 1916c:6). 
Vanweë die teenspoed van S.J. du Toit se vertaling en die proefuitgawe van 1922, het die vertalers uiteindelik besluit om die Griekse teks as grondteks vir die vertaiing van die Nuwe Testament te gebruik. Vrees dat die vertaiing verwerp sou word as sekere bekende gedeeltes, wat in die Statevertaling voorgekom het, nie meer in die Afrikaanse Bybel sou voorkom nie, het die vertalers laat besluit om die Textus Receptus, wat reeds meer as 40 jaar 'n verworpe teks was, te gebruik (Du Toit, 1916b:3). Kritiek van binne en buite die vertalerskring, onder andere van die hoogaangeskrewe F.W. Grosheide uit Nederland, kon die vertalers van hul besluit om die Textus Receptus as grondteks te gebruik, laat afsien nie.

Dit sou maklik wees om kritiek teen hierdie besluit uit te spreek. Uit ' $n$ tekskritiese oogpunt was dit inderdaad nie die regte besluit nie. Die vertalers het immers self toegegee dat die Textus Receptus nie die beste beskikbare teks van die Nuwe Testament was nie. Wat egter in berekening gebring moet word, is dat die vertalers midde-in die taalstryd van die eerste gedeelte van die eeu gestaan het en die gevoel van die volk teenoor die Bybel enersyds, maar ook Afrikaans andersyds, goed geken het. Dit sou inderdaad dwaas van hulle wees om 'n kritiese teks te gebruik en die gevaar te loop dat die Afrikaanse Bybel na soveel jare van stryd om 'n tegniese rede deur die volk verwerp word. In die lig hiervan is hul optrede heeltemal aanvaarbaar.

Die vertalers van die Bybel het dus die Textus Receptus as die grondteks vir hulle vertaling gebruik. Dit is ' $n$ teks wat aan die begin van die sewentiende eeu gepubliseer is. Sodoende het hulle die navorsing en die resultate van die navorsing van meer as 300 jaar buite rekening gelaat. Tekskrities was die teks wat vir die vertaiing van die Nuwe Testament van 1933 gebruik is, 'n swak en onbetroubare teks.

\subsection{Die Nuwe Vertaling van 1979}

$\mathrm{Na}$ die verskyning van die hersiene uitgawe van die Afrikaanse Bybel in 1953, is daar sterk in die rigting van 'n nuwe vertaling van die Bybel begin dink. In Oktober 1958 kom afgevaardigdes uit die drie Afrikaanse Kerke oor hierdie saak byeen. Die vraag na die grondteks van die Nuwe Testament kom spoedig na vore en afgevaardigdes was dit eens dat die beste beskikbare kritiese teks vir die vertaiing van die Nuwe Testament gebruik moes word (kyk Jordaan, 1975:96 - 101). 
Die verskyning van die eerste uitgawe van die Bybelgenootskap se teks in 1966 het die vertalers laat besluit om hierdie teks te gebruik. Een van die redes was sekerlik die feit dat hierdie teks spesifiek met die oog op die Bybelvertaling saamgestel is. Toe die tweede verbeterde uitgawe van hierdie teks in 1968 verskyn, is dit uiteraard deur die vertalers gebruik. Omdat die vertaling van die Nuwe Testament feitlik afgehandel was toe die derde uitgawe van hierdie teks in 1975 verskyn het, kon die vertalers hierdie teks nie ten voile benut nie. Volgens die voorwoord van die Blye Boodskap is die verskille tussen die tweede en derde uitgawes van die teks van die Verenigde Bybelgenootskappe, in die nuwe vertaling bygewerk. Die nuwe vertaling van die Nuwe Testament in 1979 gaan dus terug op die beste beskikbare kritiese uitgawe van die $20 \mathrm{e}$ eeu, waarin die resultate van die navorsing van die afgelope drie en meer eeue op die gebied van die Nuwe-Testamentiese Tekskritiek verdiskonteer is. Die vertalers verdien lof vir hierdie besluit.

'n Woord van waarskuwing is egter hier paslik. Alhoewel hierdie teks veel nader aan die oorspronklike staan as die Textus Receptus, is dit oordrewe om te beweer dat die teks van die Nuwe Testament vandag met 'n sekerheidsgraad van $99 \%$ vasstaan (kyk bv. Groenewald, 1969:196). Die talle resensies van hierdie teks ontbloot veel tekortkominge en swakhede. Wie met hierdie teks werk, moet hom deeglik van hierdie kritiek vergewis en daarmee rekening hou.

\subsection{Verskille tussen die vertalings van 1933 en 1979}

In 1969, ses jaar voor die verskyning van die Blye Boodskap, waarsku Groenewald in verband met die gebruik van 'n nuwe grondteks dat "in sekere gevalle uitsprake wat diep gewortel geraak het in die godsdienstige gemoed, prysgegee sal moet word. 'n Mens huiwer om hieraan aandadig te moet wees. Tog is dit die eis van die eerlikheid en daaraan moet ons gehoorsaam bly. Dit is immers die eis wat die Woord van God self stel. Die waarheid, soos dit aan ons bekend is, moet geërbiedig word" (Groenewald 1969:200). In die voetnotas van die Nuwe Vertaling word na enkele van hierdie gevalle verwys (kyk Mt 6:13; 17:21; 18:11; 23:14; Mk 7:16; 9:44, 46; 11:26; 16;9 - 20; Lk 17:36; 23:17; Jh 5:4; 7:53 - 8:11; Hd 8:37; $15: 34 ; 24: 7 ; 28: 29 ; \mathrm{Rm} 16: 24)$. Hierdie lys kan nog veel langer gemaak word. Die samestellers van die teks van die Verenigde Bybelgenootskappe het byvoorbeeld meer as 1,440 sulke gevalle by hulle teks ingesluit. Hierdie is slegs die belangrikste probleme 
wat aan die vertaling van die Nuwe Testament verskil maak. Die volgende kort bespreking van drie tekskritiese probleme in die Griekse Nuwe Testament is ' $n$ voorbeeld van die wyse waarop hierdie probleme opgelos kan word.

\subsection{Matteus 6:13}

In die tekskritiese apparaat van die teks van die Verenigde Bybelgenootskappe (1975) word sewe variante lesings in hierdie vers aangedui. Die meeste lesings kom egter slegs in die oudste vertalings van die Griekse Nuwe Testament en nie in die manuskripte voor nie. Uiteindelik is daar twee belangrikse lesings wat die kern van die probleem vorm:

- " ... verlos ons van die Bose." Vers 14 volg onmiddellik (Nuwe Vertaling).

- " ... verlos ons van die Bose, want aan $U$ behoort die Koninkryk en die krag en die heerlikheid tot in ewigheid. Amen." Vers 14 volg hierna(Ou Vertaling).

Wanneer die manuskripte waarin hierdie twee lesings voorkom, ontleed word, is dit duidelik dat die lesing van die Nuwe Vertaling (die kort lesing) waarskynlik die oorspronklike is. Hierdie lesing kom in die oudste en beste manuskripte (bv. codex Sinaiticus en Vaticanus uit die vierde eeu) voor, terwyl die lang lesing (van die Ou vertaling) nie in een van die oudste of beste manuskripte voorkom nie. 'n Tweede belangrike argument ten gunste van 'n kort lesing, is dat vers 14 eerder by die gebed om sondevergiffenis en verlossing van die Bose, as by die lofverheffing aansluit. Sou die lofverheffing (die woorde van die ou vertaling) voor vers 14 ingevoeg word, word die gang van die passasie ietwat onderbreek en ontstaan daar iets van 'n gedagtesprong. Waarom sou iemand dan hierdie woorde by die Evangelie wou byvoeg as dit nie oorspronklik daar gestaan het nie? Die volgende bied 'n verklaring: Joodse gebede het gewoonlik met so 'n doksologie afgesluit. Sonder die doksologie eindig die gebed van die Here ietwat stomp. 'n Teksoorskrywer kon dus gedink het dat daar oorspronklik wel so 'n doksologie aan die einde van die gebede gestaan het, maar dat dit op een of ander wyse uit die manuskrip wat hy voor hom gehad het, weggelaat is. So het hy dan, moontlik na aanleiding van 1 Kron 29 ; 11 - 13, moontlik na aanleiding van 'n bekende formuliergebed, die betrokke woorde in sy teks ingevoeg. Tekskopieerders wat weer 
hierdie manuskrip gebruik het, het hierdie woorde by hul manuskripte ingesluit. So is die woorde van geslag tot geslag oorgedra en het dit uiteindelik ook in die Textus Receptus, en vandaar in die Ou Afrikaanse Bybel beland.

\subsection{Markus $16: 9-20$}

Die slot van die Evangelie volgens Markus bied een van die interessantste, maar ook die moeilikste tekskritiese probleme. In die "Nuwe Testament en die Psalms" word Markus 16: 9 - 20 tussen blokhakies geplaas. Die "Blye Boodskap" voeg ook nog 'n gedeelte na vers 20 in. Hierdie woorde is van 'n voetnota voorsien wat dit as die "kort" einde aandui. Die Nuwe Afrikaanse Bybel van 1983 het slegs 'n voetnota by hierdie woorde. Die vraag is dus: waar eindig die Evangelie volgens Markus? Eindig dit by:

- vers 8 " ... want hulle was bang." (die stomp slot)?

- vers 20 " ... wat daarop gevolg het." ( die lang slot)?

- vers '9' " ... laat verkondig." ( die kort slot)?

Uit 'n ontleding van die manuskripte waarin hierdie lesings voorkom, blyk dit dat die kort slot buite rekening gelaat kan word, omdat dit in nóg een van die beste, nóg een van die oudste manuskripte voorkom.

Daar moet dus tussen die lang en stomp slot van hierdie Evangelie gekies word. Albei hierdie lesings kom in van die oudste manuskripte voor: Die stomp slot kom in codex Sinaiticus en Vaticanus ( uit die vierde eeu) voor, tersyl die lang slot in codex Alexandrinus en Beza (uit die vyfde eeu) voorkom. Hoewel die lang slot in meer van die oudste manuskripte voorkom, kom die stomp slot in albei die betroubaarste manuskripte (codex Sinaiticus en Vaticanus) voor. Ten gunste van die stomp slot tel ook die feit dat daar talle woorde en uitdrukkinge wat nêrens elders in die Markus-Evangelie voorkom nie, en wat duidelik nie eie aan Markus se styl is nie, in vers $9-20$ voorkom. Hieraan kan met 'n groot mate van sekerheid gesien word dat Markus waarskynlik nie die skrywer van hierdie woorde was nie.

Steeds is die probleem egter nie opgelos nie. Juis die "stompheid" van die stomp slot, roep sekere vrae na vore. In die Griekse teks eindig vers 8 met 'n partikel (wat ook deur sommige as 'n 
voegwoord beskou word). In Afrikaans word hierdie woord gewoonlik met "want" of "immers" vertaal. Dit sou hoogs uitsonderlik wees as ' $n$ boek met so ' $n$ woord eindig. Juis hierdie feit kon egter ook ' $n$ teksoorskrywer laat besluit het dat Markus sy werk nie so sou eindig nie en dat die eintlike slot op een of ander wyse ontbreek het. Om hierdie rede het hy toe waarskynlik so 'n slot na aanleiding van die ander Evangelies se eindes saamgestel en dit by sy manuskrip ingesluit. Of die Evangelie volgens Markus werklik by vers 8 geëindig het en of die oorspronklike einde verlore is, is baie moeilik om met die inligting wat vandag tot tekskritici se beskikking is, te bepaal. Wat egter tog duidelik is, is dat die lang tradisionele slot (van die Ou Vertaling) waarskynlik nie outentiek is nie.

\section{Johannes 5: 7 - 8}

Hierdie tekskritiese probleem is seker een van die bekendste probleme in die Griekse Nuwe Testament. Twee variante lesings kom in 1 Johannes $5: 7$ - 8 voor:

- "Daar is drie wat getuig: die Gees en die water en die bloed, en die drie se getuienis stem ooreen." (Nuwe Vertaling).

- "Want daar is drie wat getuig in die hemel: Die Vader, die Woord en die Heilige Gees, en hierdie drie is Een; en daar is drie wat getuig op aarde: die Gees, die water en die bloed, en die drie is eenstemmig." (Ou Vertaling).

'n Ontleding van die manuskripte waarin hierdie woorde voorkom, toon aan dat dit baie onwaarskynlik is dat die lang lesing (van die Ou vertaling) deel van die oorspronklike was. Die lesing van die ou vertaling (wat bekend staan as die "drie Hemelse Getuies") kom slegs in ses Griekse manuskripte voor. In drie van hierdie manuskripte staan dit in die kantlyn geskryf - 'n aanduiding dat die teksoorskrywer wat hierdie manuskripte voortgebring het, hierdie woorde geken het, maar nie seker was of hulle inderdaad deel van die oorspronklike teks was nie. Die oudste van hierdie manuskripe dateer maar uit die twaalfde eeu. Benewens hierdie manuskripte kom hierdie woorde egter ook in 'n aantal ou Latynse vertalings van die Nuwe Testament sowel as in die Vulgata (amptelike Latynse Bybel van die Westerse Kerk in die Middeleeue), voor. Nieteenstaande al hierdie getuienis teen hierdie woorde, het dit tog 'n plek in die ou vertaling en baie ander "groot" vertalings van die wêreld verkry. 
Hierdie lesing het egter ' $n$ interessante geskiedenis. Toe Erasmus sy teks in 1516 gepubliseer het, het die betrokke woorde in sy eerste uitgawe ontbreek. Die ontbreking van hierdie woorde het die spanning tussen Erasmus en Stunica, wat die teks van die Griekse Nuwe Testament vir kardinaal Ximenes voorberei het, veroorsaak, onder andere omdat dit die gronde vir die leerstuk oor die Drie-eenheid van God sou verwyder. Stunica dring toe daarop aan dat Erasmus die woorde by sy volgende uitgawe insluit. Erasmus weier om dit te doen, tensy iemand ' $n$ Griekse manuskrip met die woorde in aan hom sou voorsien. Spoedig voldoen iemand aan sy versoek en bring vir hom 'n manuskrip uit die sestiende eeu (!) waarin die betrokke woorde voorkom. Waarskynlik is die betrokke woorde uit die Vulgata (Latyn) in Grieks terugvertaal en by hierdie manuskrip ingesluit met die doel om aan Erasmus se voorwaarde te voldoen. Alhoewel Erasmus agterdogtig was toe hierdie manuskrip aan hom gegee is, het hy hierdie woorde tog by sy teks ingesluit. Uiteindelik is dit ook in die Textus Receptus, die grondteks van die $\mathrm{Ou}$ Afrikaanse Vertaling, opgeneem en so het dit ook in die Afrikaanse Bybel beland. Vandag is daar egter min of meer eenstemmigheid onder tekskritici dat hierdie woorde nie deel van die oorspronklike Johannes-brief was nie.

\section{Ten slotte}

Norval (1971: 10 - 11) sê: "Dit bly die verantwoordelikheid van die kerk om vir sy lidmate die Bybel te voorsien wat so na as moontlik aan die autografa staan en met die huidige kennis van die Griekse taal asook die Afrikaanse taal en met die baie manuskripte, vertalings en sitate uit die vroeëre kerkvaders kan tekskritici 'n meer verantwoorde vetaling van die Nuwe Testament in Afrikaans daarstel as in 1933." In die 1979-vertaling het die Afrikaanse Kerke 'n vertaling waarin op 'n uitnemende wyse aan hierdie vereistes voldoen is en ondanks die vreemdheid van 'n "Ons Vader" sonder die lofverheffing (Mt 6: 13) of die doop van 'n bekeerde sonder 'n geloofsbelydenis ( $\mathrm{Hd} \mathrm{8:37)}$ of 'n eerste Johannesbrief sonder die "drie Hemelse Getuies" (1 Jh 5:7 - 8) gaan hierdie vertaling terug op 'n grondteks wat waarskynlik nader as ooit aan die oorspronklike woorde van die Nuwe Testament staan. 
Geraadpleegde werke

Slegs werke warna direk verwys word, is hierby ingesluit.

ALAND, $K$ en ALAND, B. 1982

Der Text des Neuen Testaments. Stuttgart: Deutsche Bibelgesellschaft.

ALAND, K. et al. (red.).

The Greek New Testament. (3e uitg.) New York: United Bible Societies.

BURGON, J.W. 1883.

The Revision Revised. London: G. Bell.

DU TOIT, J.D. $1916 a$.

Het Kerkblad. 1 Augustus 1916

DU TOIT, J.D.1916b.

Bijbelvertaling. Het Kerkblad 1 September 1916.

DU TOIT, J.D. $1916 \mathrm{c}$.

Het Kerkblad 1 Oktober 1916.

GROENEWALD, E.P. 1969.

Die Nuwe Bybelvertaling. Tydskrif vir Geesteswetenskappe

9. $193-207$.

JORDAAN, G.J.C. 1975.

Die bronne waaruit die Nuwe Testament van die Afrikaanse Bybel vertaal is. Potchefstroom. Ongepubliseerde M.A.-verhandeling.

METZGER, B.M. 1968.

The Text of the New Testament. Oxford: Clarendon Press. 
NIENABER, P.J. en HEYL, J.A. 1961

Die Afrikaanse Bybelvertaling. Kaapstad: Nasionale Boekhandel.

N'ORVAL, E.J.G. 1971.

Nuwe vertaling van die Afrikaanse Bybel - Textus Receptus vaarwel. Bulletin van die SAVCW 27, 3 - 11. 